\title{
Time and temperature dependent sorption behaviour of dimethoate pesticide in various Indian soils
}

\author{
Sunita Rani* and Dhiraj Sud \\ Sant Longowal Institute of Engineering and Technology, Longowal, Sangrur, Punjab INDIA
}

Received August 27, 2013; accepted September 3, 2014

\begin{abstract}
A b s t r a c t. Experiments were conducted to study the sorption behaviour of dimethoate in three Indian soils at different temperatures. A kinetic study showed that adsorption equilibrium was reached within $15 \mathrm{~h}$ at different initial levels of pesticide concentration. Applicability of the pseudo second order kinetic model suggested that the adsorption process was complex and several mechanisms were involved. The Freundlich model explained the adsorption behaviour adequately and the isotherms were of S-type. The adsorption process was found to be strongly affected by temperature. The Gibbs free energy change, $\Delta \mathrm{G}^{\mathrm{o}}$ values (from -15.81 to $-16.60 \mathrm{~kJ} \mathrm{~mol}^{-1}$ ) indicated that the process was spontaneous and exothermic in nature. The change in enthalpy of adsorption, $\Delta \mathrm{H}^{\circ}$ values (from -17.729 to $-21.539 \mathrm{~kJ} \mathrm{~mol}^{-1}$ ) suggested that relatively weak H-bond forces were the main driving forces for adsorption. Desorption was found to be concentration- and temperature-dependent with higher desorption occurring at higher temperature and concentration levels. The results signify the importance of temperature in controlling the mobility of dimethoate in water bodies.

Keyw ords: dimethoate, isotherms, kinetics, sorption, thermodynamics
\end{abstract}

\section{INTRODUCTION}

Dimethoate is a widely used organophosphate pesticides for control of red spider mite in cucurbits, jassids and aphids in okra (bhindi) and potato, thrips in pea, and citrus psylla and aphids in citrus and other fruits. The Environment Protection Agency (EPA) classifies dimethoate as a class II toxicity-moderate toxic compound. It is highly soluble $\left(25 \mathrm{~g} \mathrm{l}^{-1}\right.$ in water at $\left.21^{\circ} \mathrm{C}\right)$ in water. Although dimethoate is quite an old pesticide, very few studies are available on its adsorption behaviour on soils (Kuisi, 2002; Vagi et al., 2010). Moreover, only one published study is avail- able on desorption of dimethoate from the soil (Vagi et al., 2010). The presence of dimethoate residues has been reported in groundwater and soil (Vig et al., 2001; Batista et al., 2002). No work has yet been reported on adsorption as well as desorption of dimethoate on Indian soils of the Punjab region, which are characterized by low organic matter and clay content, the primary controlling factors for adsorption process. In order to describe the adsorption phenomenon, it is necessary to obtain information about the relationships at equilibrium between the amount adsorbed and the concentration of the bulk solution in contact with the adsorbent, the energies that characterize the equilibrium between the solid surface and the liquid phase, and the speed at which equilibrium is attained along with the magnitude of energies involved. Literature data concerning the kinetics of adsorption and temperature effect on sorption of dimethoate is totally absent. The kinetic study provides useful information for designing and modelling the adsorption processes. Thermodynamic studies can be useful for indication of predominant forces and reversibility of the binding forces. This can in turn help in predicting the pesticide mobility in the soil on which it is applied as well as the potential surface and groundwater contamination. Therefore, the present work was carried out to study the adsorption kinetics, effect of temperature on sorption behaviour, and leaching potential of dimethoate under laboratory conditions on three Indian agricultural soils from Punjab region (India) with different physical and chemical characteristics. 


\section{MATERIALS AND METHODS}

The technical grade standard ( $>99.5 \%$ purity) of dimethoate (O,O-dimethyl S-methylcarbamoylmethyl phosphorodithioate) was obtained from Sigma Aldrich, Bangalore (India), and was used without any further purification for the present study.

Three cultivated soils of different regions of Punjab, India, were selected and collected from the surface layer of soil $(1-15 \mathrm{~cm})$. The soils were air dried, stirred, crushed, and sieved to pass through $2 \mathrm{~mm}$ sieve to maintain a uniform particle size. The adsorption experiments were conducted on the dried soil under laboratory conditions. Drying and sieve analysis of the soils were done to obtain uniformity in the results of adsorption experiments for better comparison. Soil samples were classified based on textural analysis and according to United States Department of Agriculture (USDA) particle size classification (clay $<2 \mu \mathrm{m}$; silt $2-50 \mu \mathrm{m}$ and sand 50-2000 $\mu \mathrm{m}$ ). Particle size distributions were performed using the hydrometer method (Bouyoucos, 1962). Soil $\mathrm{pH}$ was measured in water in 2:5 ratio of soil suspension using a combination glass electrode. The organic matter (OM) content of the soil was determined by a modified Walkley and Black method and organic matter was calculated by multiplying organic carbon by 1.72 (Carter, 1993). The electrical conductivity was measured in 1:5 (soil:water) soil water suspension using a conductivity meter. The heavy metals were extracted and analyzed following IS 11466:1995. (http://www.iso.org/iso/catalogue_detail.htm?csnumber= 19418). Physicochemical properties of the tested soils are presented in Table 1.

Kinetics experiments were carried out in $15 \mathrm{ml}$ polypropylene centrifuge tubes at an initial dimethoate concentration of $5,10,15$, and $20 \mathrm{mg} \mathrm{l}^{-1}$ at $30 \pm 1^{\circ} \mathrm{C}$ for all the soils. Pesticide dilutions were prepared in a $0.01 \mathrm{M} \mathrm{CaCl}_{2}$ aqueous solution in order to maintain constant ionic strength as it minimizes cation exchange and improves the centrifugation procedure. Each mixture consisted of $1 \mathrm{~g}$ of soil mixed with $10 \mathrm{ml}$ of the pesticide solution in a centrifuge tube and sealed with screw caps with Teflon lining. The experiments were performed by stirring the suspensions at 100 r.p.m. for different time durations $(1,2,4,6,8,10,15$,
20, and $24 \mathrm{~h}$ ). Thereafter, the tubes were centrifuged for $30 \mathrm{~min}$ at 4500 r.p.m. The supernatant was poured off for determination of the pesticide concentration.

The adsorption experiments were performed according to the Organization for Economic Co-operation and Development Guideline 106 (OECD, 2000). Pesticide dilutions were prepared exactly the same way as in the kinetics experiment. Six concentrations of 1, 2, 5, 10, 15, and $20 \mathrm{mgl}^{-1}$ were used for all soils. Time required for the pesticide to attain adsorption equilibrium was determined as per the kinetics study. The centrifuge tubes were gently shaken for the required time at $100 \mathrm{rpm}$ at three temperatures $20 \pm 1$, $30 \pm 1$, and $40 \pm 1^{\circ} \mathrm{C}$. Thereafter, these tubes were centrifuged for 30 minutes at 4500 r.p.m. The clear supernatant was poured off for determination of the equilibrium concentration $\left(C_{e}\right)$ of the pesticide. The adsorption was performed in two replicates. One blank (without pesticide) and one control (without soil) were included in each sample batch to assure the quality control of the experiments. For the desorption study, the supernatant removed was replaced with the same volume of the $0.01 \mathrm{M} \mathrm{CaCl}_{2}$ aqueous solution. The tubes were mechanically shaken for $10 \mathrm{~h}$ at 100 r.p.m. as per the preliminary kinetics studies of desorption equilibrium (results of desorption kinetics are not presented) at the desired temperatures. Thereafter, the tubes were centrifuged for $30 \mathrm{~min}$ at 4500 r.p.m. The supernatant was poured off for determination of the pesticide concentration (pesticide desorbed).

Analysis of dimethoate extracted was performed on HPLC (Shimadzu Corporation, Japan). The chromatographic system consisted of a Shimadzu-LC 20AT pump, the stationary phase was $\mathrm{C} 18$, Phenomenex Luna $5 \mu \mathrm{m}$ 100A 250 X $4.6 \mathrm{~mm}$ analytical column, and the detector used was SPD-20A (UV-VIS detector). An isocratic elution method in a mobile phase consisting of water: acetonitrile $(60: 40 \% \mathrm{v} / \mathrm{v})$ at a flow rate of $1 \mathrm{ml} \mathrm{min}^{-1}$ was used. The injection volume was $10 \mu 1$ and the detection wavelength was $221 \mathrm{~nm}$. The supernatant obtained in the kinetics, batch adsorption and desorption experiments as discussed earlier was filtered through a syringe filter $(0.2$ micron $)$ before being injected into the HPLC column.

T a b l e 1. Physicochemical properties of soils under study

\begin{tabular}{|c|c|c|c|c|c|c|c|c|c|c|c|}
\hline \multirow{2}{*}{$\begin{array}{l}\text { Soil } \\
\text { No. }\end{array}$} & \multirow{2}{*}{$\begin{array}{l}\text { Type } \\
\text { of soil }\end{array}$} & \multicolumn{3}{|c|}{$\begin{array}{l}\text { Textural analysis } \\
\qquad \%)\end{array}$} & \multirow{2}{*}{$\begin{array}{l}\text { Electrical } \\
\text { conductivity } \\
\left(\mathrm{mS} \mathrm{cm}^{-1}\right)\end{array}$} & \multirow{2}{*}{$\mathrm{pH}$} & \multirow{2}{*}{$\begin{array}{c}\text { Organic } \\
\text { matter } \\
(\%)\end{array}$} & \multicolumn{4}{|c|}{ Mineral content $\left(\mathrm{kg} \mathrm{ha}^{-1}\right)$} \\
\hline & & Sand & Silt & Clay & & & & $\mathrm{Zn}$ & $\mathrm{Cu}$ & $\mathrm{Fe}$ & $\mathrm{Mn}$ \\
\hline A & Loam & 40 & 49 & 11 & 0.095 & 6.7 & 0.57 & 8.5 & 10.6 & 21.9 & 19.4 \\
\hline B & Loamy sand & 77 & 17 & 6 & 0.233 & 8.4 & 0.67 & 8.1 & 4.2 & 33.0 & 20.7 \\
\hline $\mathrm{C}$ & Sandy loam & 60 & 35 & 5 & 0.046 & 8.1 & 0.52 & 8.0 & 11.8 & 22.6 & 16.8 \\
\hline
\end{tabular}


Quantification of the analytes was carried out by integration of peak areas. Quantification or recovery of the pesticides in the fortified samples was performed by comparing the detector responses for the target compound in samples with those measured in calibration standards solutions, according to the equation of the appropriate calibration curve.

From the data obtained from the batch adsorption experiments, the amount of pesticides adsorbed on the soil at equilibrium $\left(Q_{e}, \mathrm{mg} \mathrm{kg}^{-1}\right)$ was calculated as:

$$
Q_{e}=\frac{\left(C_{o}-C_{e}\right) V}{m}
$$

where: $C_{o}$ is the initial and $C_{e}$ is the final equilibrium concentration of the pesticide $\left(\mathrm{mg} \mathrm{l}^{-1}\right), V$ is the volume of the pesticide solution (l), and $m$ is the soil mass in contact with the pesticide $(\mathrm{kg})$. $C_{e}$ was found out using HPLC as discussed above.

From the desorption study, the amount of dimethoate retained by the soil $\left(Q_{e}^{\text {des }}, \mathrm{mg} \mathrm{kg}^{-1}\right)$ was calculated as the difference between the initial adsorbed amount and the desorbed amount $\left(C_{e}^{\text {des }}, \mathrm{mg}^{-1}\right)$ :

$$
Q_{e}^{\text {des }}=\frac{\left(C_{e}-C_{e}^{\text {des }}\right) V}{m} .
$$

\section{RESULTS AND DISCUSSION}

The adsorption studies were performed on the dried soils to obtain uniformity in the results and to minimize the effect of soil moisture on the adsorption process. The adsorption results of the soils under natural conditions could have been different due to the varying agricultural practices, weather and soil moisture etc. As studied by Calvet (1989), although soil moisture can play a role in the adsorption process, such experiments are very difficult to design. Some researchers (Hance, 1977; Yaron and Satlzman, 1972) have found that adsorption coefficients increased with a decrease in soil water content. However, the present study primarily focuses on the effect of temperature with respect to adsorption.

The graph showing the adsorption of dimethoate with respect to time for soil A (loamy soil) is presented in Fig. 1. At all the initial concentration levels, the initial rate of adsorption was very fast and more than 50 and $90 \%$ adsorption took place within the first hour and $9 \mathrm{~h}$, respectively. The second phase of adsorption was very slow, but at all the concentration levels; equilibrium was reached within $15 \mathrm{~h}$. The rapid initial adsorption is a surface phenomenon where vacant sites in the soil particles were filled up rapidly in the initial stages and followed a linear variation. This was followed by a slow migration and diffusion of pesticide molecules in soil (Gao et al., 1998). Moreover, at lower initial concentrations ( 5 and $10 \mathrm{mg} \mathrm{l}^{-1}$ ), equilibrium was reached fast as compared to those of higher initial con-

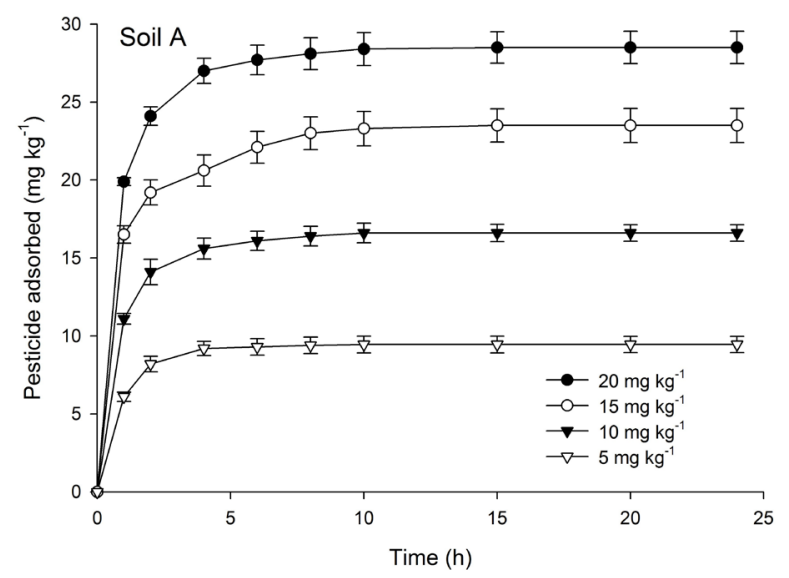

Fig. 1. Adsorption kinetics of dimethoate in soil $\mathrm{A}$ at different initial concentration levels and at $30^{\circ} \mathrm{C}$ (Error bars show standard deviation).

centrations ( 15 and $\left.20 \mathrm{mg} \mathrm{l}^{-1}\right)$. Similar trends were observed for soils B (loamy sand) and C (sandy loam), although the amount of the pesticide adsorbed at equilibrium varied.

Three different kinetic models namely pseudo-first order, pseudo-second order kinetic (Ahmad, 2011), and Weber and Morris intra particle diffusion model (Weber and Morris, 1963) were applied to the adsorption data in order to study the mechanism involved in the adsorption process. The pseudo first-order equation describes adsorption in solid-liquid systems based on the sorption capacity of solids. The pseudo second-order rate equation assumed that the adsorption mechanism was dominant by chemisorptions. The pseudo first order and second order kinetic models can be expressed as:

$$
\begin{gathered}
\ln \left(Q_{e}-Q_{t}\right)=\ln Q_{e}-k_{1} t, \\
\frac{t}{Q_{t}}=\frac{1}{k_{2} Q_{e}^{2}}+\frac{t}{Q_{e}},
\end{gathered}
$$

where: $Q_{t}$ is the amount of the pesticide $\left(\mathrm{mg} \mathrm{kg}^{-1}\right)$ adsorbed at time $t(\mathrm{~h}), k_{1}$ is the rate constant of pseudo-first order adsorption $\left(\mathrm{h}^{-1}\right)$, and $k_{2}$ is the pseudo-second order rate constant $\left(\mathrm{kg} \mathrm{mg}^{-1} \mathrm{~h}^{-1}\right)$.

The best-fit kinetic model was selected on the basis of linear regression correlation coefficient ( $\mathrm{R}^{2}$ values) and standard error of estimate ( $S E E$ ) value. These values along with the model constants are given in Table 2. The pseudo first order model as well as the second order model were fitted well with the experimental results although the second order rate equation gave relatively higher $\mathrm{R}^{2}$ and very low $S E E$ values. The perfect fit of the experimental data for the pseudo second order rate equation indicates the applicability of the model. This indicates that the adsorption was a complex process and several mechanisms were involved 
(Peng et al., 2012). Moreover, in the chemisorption process, the pseudo second order is superior to the pseudo-first order model because it deals with interaction of adsorbent-adsorbate through their valency forces (Bajeer et al., 2012). Therefore, the rate-limiting step may be chemical adsorption.

The fitting of the kinetic models was checked by the coefficient of determination $\left(\mathrm{R}^{2}\right)$ and $S E E$. The $S E E$ value presents a measure of agreement between the calculated and the observed values and is defined by:

$$
S E E=\sqrt{\frac{\sum\left(q_{\text {texp }}-q_{\text {tal }}\right)^{2}}{n-2}} .
$$

where: $q_{\text {texp }}$ and $q_{\text {tcal }}$ are the experimental and calculated adsorbed amounts of dimethoate in soil at time $t$, respectively, and $n$ is the number of measurements.

The kinetic data was also subjected to Weber and Morris intraparticle diffusion model in order to explore the possibility of intraparticle diffusion on adsorption. The linear form of the model is given by:

$$
Q_{t}=K t^{0.5}
$$

where: $K\left(\mathrm{mg} \mathrm{kg}^{-1} \mathrm{~h}^{0.5}\right)$ is the intraparticle diffusion rate constant.
Intra-particle diffusion plays a significant role in controlling the kinetics of the sorption process when the plot is linear and passes through the origin (Oladoja et al., 2008). The curve obtained did not pass through the origin implying that the intraparticle diffusion was not the only operative mechanism (figure not shown). Furthermore, the plots exhibited an initial linear portion followed by a plateau. The initial curved portion of the plots are attributed to the diffusion of the adsorbate through the solution to the external surface of the adsorbent or the boundary layer diffusion of the solute molecules. The plateau could be attributed to the final equilibrium stage where intraparticles start to slow down due to the extremely low adsorbate concentration in solution. However, the plot did not pass through the origin, indicating that although intraparticle diffusion was involved in the adsorption process, it was not the rate-controlling step.

To describe the adsorption processes of dimethoate, three different non-linear isotherm models namely Freundlich, Langmuir, and Temkin were used.

Different adsorption isotherm models such as the Langmuir, Freundlich and Temkin models were used on the adsorption data. The Langmuir model is valid when the adsorption involves the attachment of only one layer of molecules to the surface and the surface has a specific

T a b l e 2. Coefficients of adsorption kinetic models, standard errors of estimate (SEE), and coefficients of determination $\left(\mathrm{R}^{2}\right)$ for

\begin{tabular}{|c|c|c|c|c|c|c|c|c|c|}
\hline \multirow{2}{*}{$\begin{array}{l}\text { Soil } \\
\text { No. }\end{array}$} & \multirow{2}{*}{$\begin{array}{c}\text { Initial } \\
\text { concentration } \\
C_{i}\left(\mathrm{mg} \mathrm{l}^{-1}\right)\end{array}$} & \multicolumn{3}{|c|}{ Pseudo first order model } & \multicolumn{3}{|c|}{ Pseudo second order model } & \multicolumn{2}{|c|}{$\begin{array}{c}\text { Intra particle diffusion } \\
\text { model }\end{array}$} \\
\hline & & $\mathrm{k}_{1}\left(\mathrm{~h}^{-1}\right)$ & $\mathrm{R}^{2}$ & SEE & $\begin{array}{c}\mathrm{k}_{2} \\
\left(\mathrm{~kg} \mathrm{mg}^{-1} \mathrm{~h}^{-1}\right)\end{array}$ & $\mathrm{R}^{2}$ & SEE & $\begin{array}{c}\mathrm{k} \\
\left(\mathrm{mg} \mathrm{kg}^{-1} \mathrm{~h}^{0.5}\right)\end{array}$ & $\mathrm{R}^{2}$ \\
\hline \multirow{4}{*}{ A } & 5 & 0.460 & 0.975 & 0.210 & 1.561 & 1.000 & 0.190 & 1.322 & 0.943 \\
\hline & 10 & 0.311 & 0.963 & 0.455 & 0.093 & 0.999 & 0.507 & 1.834 & 0.886 \\
\hline & 15 & 0.459 & 0.938 & 1.472 & 0.061 & 0.999 & 0.870 & 2.658 & 0.894 \\
\hline & 20 & 0.428 & 0.966 & 0.641 & 0.053 & 1.000 & 0.228 & 3.357 & 0.839 \\
\hline \multirow{4}{*}{ B } & 5 & 0.447 & 0.995 & 0.220 & 0.146 & 1.000 & 0.502 & 1.585 & 0.869 \\
\hline & 10 & 0.325 & 0.943 & 0.989 & 0.094 & 0.999 & 0.306 & 1.807 & 0.895 \\
\hline & 15 & 0.446 & 0.961 & 0.886 & 0.075 & 1.000 & 0.538 & 2.383 & 0.869 \\
\hline & 20 & 0.344 & 0.996 & 0.638 & 0.188 & 1.000 & 0.131 & 3.238 & 0.827 \\
\hline \multirow{4}{*}{ C } & 5 & 0.576 & 0.961 & 0.489 & 0.057 & 0.999 & 0.313 & 1.356 & 0.738 \\
\hline & 10 & 0.452 & 0.987 & 0.529 & 0.306 & 1.000 & 0.243 & 2.299 & 0.827 \\
\hline & 15 & 0.385 & 0.982 & 0.586 & 0.046 & 1.000 & 0.646 & 2.421 & 0.879 \\
\hline & 20 & 0.461 & 0.985 & 0.595 & 0.051 & 1.000 & 0.552 & 2.742 & 0.746 \\
\hline
\end{tabular}
dimethoate on different soils under study 
number of sites where the solute molecules can be attached (Giles et al., 1960). The isotherm is given by the linearized form of Eq. (7):

$$
\frac{C_{e}}{Q_{e}}=\frac{1}{Q_{0} b}+\frac{C_{e}}{Q_{0}}
$$

where: $Q_{0}$ is the maximum quantity of pesticides $\left(\mathrm{mg} \mathrm{kg}^{-1}\right)$ per unit weight of the adsorbent to form a complete monolayer on the surface, $b$ is a constant related to the affinity of binding sites with the pesticide $\left(1 \mathrm{mg}^{-1}\right)$.

The Freundlich model is often used for heterogeneous adsorption (Garg et al., 2008) and is given as:

$$
Q_{e}=K_{f} C_{e}^{1 / n}
$$

where: $K_{f}$ is the Freundlich adsorption coefficient and is related to the adsorption capacity. The exponent $n$ is an adsorption constant that characterizes the adsorption intensity and energy distribution of the adsorption sites (ElShafei et al., 2009).

The Temkin isotherm model is based on the assumption that the adsorption energy decreases linearly with the surface coverage due to adsorbent-adsorbate interactions. The Temkin isotherm describes the behaviour of adsorption systems on heterogeneous surfaces. The linear form of the Temkin isotherm (ElShafei et al., 2009) is given as:

$$
Q_{e}=\frac{R T}{b} \ln \left(A C_{e}\right),
$$

where: $R$ is the gas constant $\left(8.314 \mathrm{~J} \mathrm{~mol}^{-1} \mathrm{~K}^{-1}\right), T$ is absolute temperature $(\mathrm{K}), \mathrm{b}$ is the Temkin constant related to the heat of sorption, and $A$ is the Temkin isotherm constant $\left(1 \mathrm{mg}^{-1}\right)$. The fitting of the isotherm models was checked by the coefficient of determination $\left(\mathrm{R}^{2}\right)$ and the standard error of estimate $(S E E)$. The $S E E$ value was calculated as:

$$
S E E=\sqrt{\frac{\sum\left(q_{m}-q_{e}\right)^{2}}{n-2}},
$$

where: $q_{m}$ and $q_{e}$ are the measured and calculated adsorbed amounts of dimethoate in soil, respectively and $n$ is the number of measurements.

The experimental data obtained from all the soils (data not shown) showed very bad fitting $\left(\mathrm{R}^{2}<0.6\right)$ to the Langmuir equation implying the inapplicability of the model. This was due to the heterogeneous nature of the soils and sediments. Table 3 gives the different constants and values of other parameters of the remaining two models. As per the $\mathrm{R}^{2}$ value, the data was better fitted to the Freundlich model as compared to the Temkin model. In addition, the $S E E$ values were relatively lower in the Freundlich model in most of the cases. Therefore, the adsorption data can be explained better using the Freundlich model at all the temperatures. This model is related to the non-ideal, reversible, and multilayer adsorption with non-uniform distribution of adsorption heat and affinities over the heterogeneous surface (Bajeer et al., 2012).

For all the three soils under study at the investigated temperatures, the adsorption plots are shown in Fig. 2. The adsorption mechanism can be understood from the shape of the adsorption isotherm although it does not give confirmation of the adsorbate-adsorbent interaction. The classification on the basis of the initial slope $d(Q) / d C_{e}$, of the adsorption isotherm has been proposed by Giles et al. (1960). These four categories are named as S-, L-, H-, and C- shape, based on the initial slope, which is important as it

\begin{tabular}{|c|c|c|c|c|c|c|c|c|c|}
\hline \multirow{2}{*}{ Soil No. } & \multirow{2}{*}{$\begin{array}{c}\text { Temperature } \\
\left({ }^{\circ} \mathrm{C}\right)\end{array}$} & \multicolumn{2}{|c|}{ Freundlich isotherm } & \multirow{2}{*}{$\mathrm{R}^{2}$} & \multirow{2}{*}{$S E E$} & \multicolumn{2}{|c|}{ Temkin isotherm } & \multirow{2}{*}{$\mathrm{R}^{2}$} & \multirow{2}{*}{ SEE } \\
\hline & & $\begin{array}{c}\Lambda_{f} \\
\left(\mathrm{mg} \mathrm{kg}^{-1}\right) / \\
\left(\mathrm{mg} \mathrm{l}^{-1}\right)^{1 / n}\end{array}$ & $1 / n$ & & & $\mathrm{RT} / \mathrm{b}$ & $\mathrm{A}\left(1 \mathrm{mg}^{-1}\right)$ & & \\
\hline \multirow{3}{*}{ A } & 20 & 2.918 & 1.026 & 0.957 & 2.54 & 10.88 & 1.497 & 0.914 & 4.55 \\
\hline & 30 & 2.313 & 1.000 & 0.983 & 2.27 & 9.08 & 1.195 & 0.947 & 2.62 \\
\hline & 40 & 1.586 & 0.999 & 0.949 & 2.08 & 6.79 & 1.123 & 0.939 & 2.03 \\
\hline \multirow{3}{*}{ B } & 20 & 3.278 & 0.997 & 0.954 & 1.75 & 11.30 & 1.369 & 0.948 & 3.47 \\
\hline & 30 & 2.518 & 0.993 & 0.969 & 2.57 & 9.33 & 1.254 & 0.960 & 2.51 \\
\hline & 40 & 1.617 & 1.026 & 0.971 & 1.86 & 7.51 & 1.067 & 0.919 & 2.68 \\
\hline \multirow{3}{*}{$\mathrm{C}$} & 20 & 2.853 & 0.956 & 0.977 & 2.28 & 9.72 & 1.305 & 0.929 & 4.32 \\
\hline & 30 & 2.008 & 1.055 & 0.974 & 2.60 & 9.25 & 1.119 & 0.941 & 2.77 \\
\hline & 40 & 1.457 & 1.077 & 0.978 & 2.23 & 7.54 & 1.034 & 0.952 & 2.10 \\
\hline
\end{tabular}
depends on the rate of change in adsorption site availability.

T a b l e 3. Adsorption isotherm model constants, coefficient of determination $\left(\mathrm{R}^{2}\right)$, and standard error of estimate (SEE) for dimethoate adsorption at different temperatures (two replications) 
Adsorption isotherms obtained for dimethoate were almost S-shaped on all the three soils under study. This shape is a common feature for adsorption of organic chemicals on soils with low organic matter (soils under study had organic matter $<0.67 \%$ ) or clay contents (the soils under study were loam, sandy loam, and loamy sand, clay content $<11 \%$ ). This isotherm type indicates a low pesticide-soil affinity at low concentrations, with strong competition with the aqueous phase, and adsorption becomes easier as the pesticide concentration in the aqueous phase increases. Vagi et al. (2010) also found the same shape of adsorption isotherms for dimethoate on Greek soils having low organic matter content and the isotherm shape changed to the L-type as the organic matter content of the soil increased. Kaur and Sud (2010) reported S-shaped isotherms for monocrotophos and dichlorovos on Indian soils having low organic matter and clay content. Furthermore, as the solution concentration increased, the adsorption of the pesticide decreased. Similar results have been reported by many researchers (Krishna and Philip, 2008; Patakioutas and Albanis, 2002).

From Fig. 2, it can be seen that adsorption of dimethoate showed a decreasing slope with increasing temperature for all the soils under study. This is also reflected by the decreasing $K_{f}$ values with an increase in temperature (Table 3), indicating that temperature strongly affected the adsorption. For example, for soil B (loamy sand), the $K_{f}$ value decreased from 3.278 to 1.617 as the temperature increased from 20 to $40^{\circ} \mathrm{C}$. The same trend was followed in soils A (loamy soil) and C (sandy soil). In the present study, the Freundlich constant $1 / n$ values (Table 3 ) were around unity in most of the cases, indicating that the isotherms were almost linear with respect to the concentration in the aqueous phase. This constant is related to the sorption site energy distribution, as well as to the heterogeneous organic matter domain, where the lower $1 / n$ values indicate a more heterogeneous sorption site distribution (Broznic and Milin, 2012).

As pesticides in soil are prone to leaching, the extent of adsorption measured by serves as one of the tools for predicting their mobility in the soil. Criteria given by Anderson et al. (1992) for soil mobility using adsorption constants are:

$K_{f}<2$ highly mobile,

$2<K_{f}<5$ mobile,

$K_{f}>5$ immobile with respect to leaching.

Therefore, dimethoate was considered to be mobile with respect to leaching in all the studied soils at lower temperature of adsorption and highly mobile at higher temperature.

The amount of organic matter (OM) greatly affects the adsorption process of the pesticides in the soil especially when present in large amounts (ElShafei et al., 2009), mainly because the particles of organic matter or clay provide the soil with an increased number of adsorptive sites onto which pesticides molecules can bind. Despite the complex-
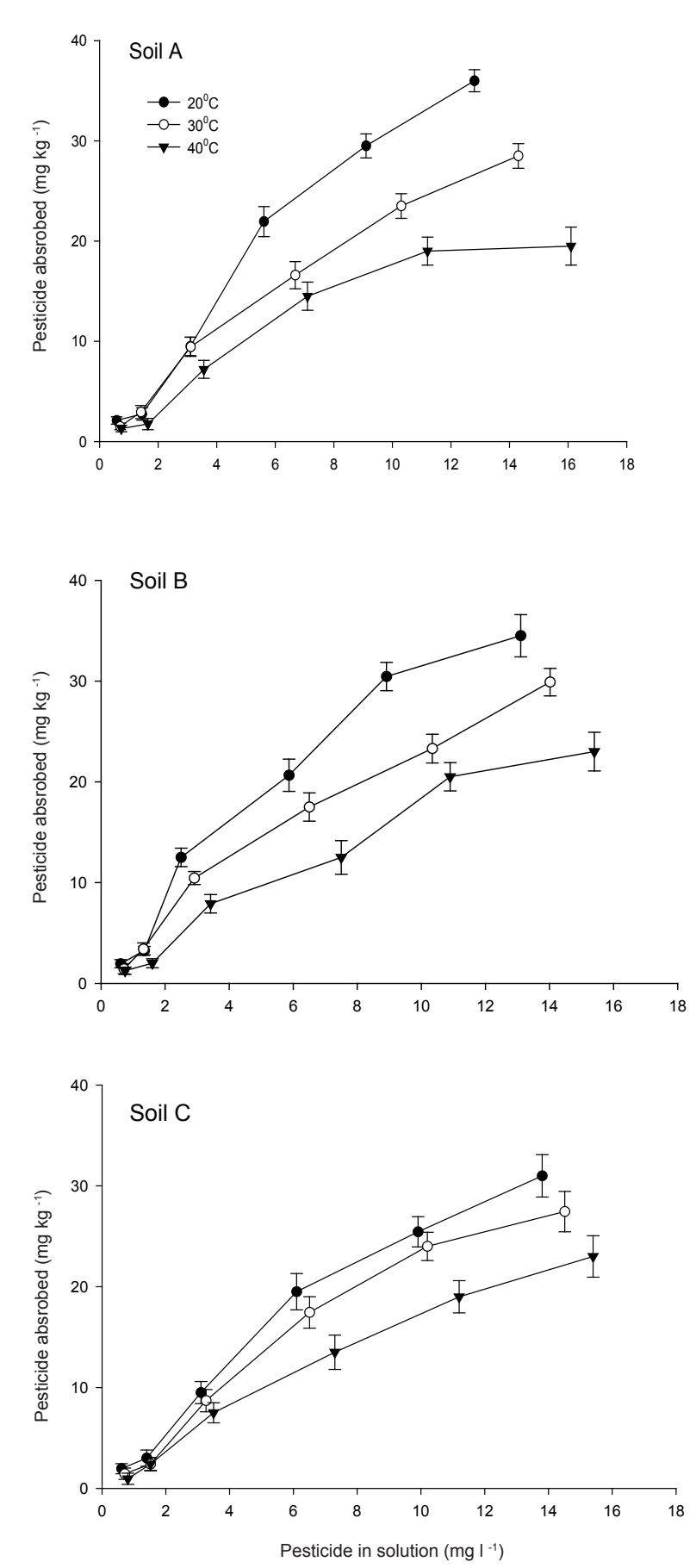

Fig. 2. Adsorption isotherm plots of dimethoate on various soils at different temperatures (error bars show standard deviation).

ity of soil organic matter compositions, it has been reported that when OM is low $(<5 \%)$, adsorption of the pesticide not only may be affected by the organic matter but also other factors such as the type and nature of the pesticide, accessibility of its functional groups, inorganic constituents, and properties of the soil may have a role to play (Von et al., 1991; Weber et al., 1991). 
The statistical correlation between $K_{f}$ values and various soil properties such as $\mathrm{OM}$, soil $\mathrm{pH}$, electrical conductivity (EC), and silt and clay content was found at the studied temperatures. The results revealed that the $K_{f}$ values were positively correlated with $\mathrm{OM}\left(\mathrm{R}^{2}>0.75\right)$ for all the temperatures. Vagi et al. (2010) have reported that organic matter as well as other soil properties played a role in adsorption of dimethoate on various Greek soils having OM varying from 1.0 to $4.2 \%$. Data from other previous studies indicate a good correlation between $K_{f}$ and OM for the organophosphate pesticides in soils having $\mathrm{OM}<1.0 \%$; the higher the organic matter, the larger the $K_{f}$ value (Garg et al., 2008; Islam et al., 2010; Ismail et al., 2002). The $K_{f}$ and EC values were also positively correlated $\left(\mathrm{R}^{2}>0.67\right)$. The higher $\mathrm{EC}$ value of soil enhances water retention by increasing the osmotic potential of the soil, thereby increasing the contacttime for adsorption (Bajeer et al., 2012). This can lead to higher adsorption by soil. ElShafei et al. (2009) have also reported that the higher the EC, the larger the $K_{f}$ value. On the other hand, no correlation could be found between $K_{f}$ and clay content. Islam et al. (2010) also showed an insignificant effect of clay content on adsorption of bromophos methyl and quinalphos on Greek soils. A possible reason for this may be involvement of both the mineral and organic components in sorption interaction of pesticides in soil. The values of $K_{f}$ and silt content were positively correlated $\left(\mathrm{R}^{2}=0.69\right)$ only at a temperature of $20^{\circ} \mathrm{C}$. No correlation could be seen at higher temperatures. Liu et al. (1970) found that adsorption of ametryne and diuron increased with an increase in silt content in the soil. Adsorption on soils and sediments is due to mineral and organic constituents, and it is often difficult to clearly separate their roles because these are always associated (Calvet, 1989). Therefore, in soil B (loamy sand), the $K_{f}$ values were higher mainly due to higher organic matter, higher electrical conductivity, and higher iron content (Table 1) indicating possible involvement of charged ionic species present in the soil causing higher adsorption. The difference in the concentration and type of metal ions in soil influences adsorption of pesticides by competitive or non-competitive complexation of heavy metal ions with soil clay minerals and organic matter (Parr and Smith, 1974). This complexation ability is reported to be higher for $\mathrm{Cu}$ (due to smaller ionic size) as compared to those of Mn and Zn ions (Lalah et at., 2009; Ryan et al., 1983). In soil $\mathrm{B}$, the concentration of $\mathrm{Cu}$ is lowest and that of Mn is highest (Table 1). This might have caused a lower inhibition effect for adsorption due to lower complexation in soil B as compared to soils A and C, resulting in a higher $K_{f}$ value in soil B. The $K_{f}$ value showed no correlation with $\mathrm{pH}$ of the soil. This may be attributed to the non-ionisable nature of the pesticide. Similar results have been reported by many researchers (Islam et al., 2010; Rotich et al., 2004) for organophosphorus pesticides.

The contribution of organic matter to sorption capacity can be quantified by a new parameter, organic matter partition coefficient, $K_{O M}$. The $K_{O M}$ value can be calculated by Eq. (11):

$$
K_{O M}=K / f_{O M},
$$

where: $f_{O M}$ is the organic matter in the soil $\left(\mathrm{g} \mathrm{g}^{-1}\right)$.

The data related to $K_{O M}$ and $\log \left(K_{O M}\right)$ is presented in Table 4 . The $K_{O M}$ of soil B was higher than for the other two soils studied for the pesticide. Pesticides with a $K_{O M}$ value below 500 are considered mobile with respect to leaching (Swann et al., 1983). According to this, dimethoate can be classified as mobile, as its adsorption was generally weak in the soils under study $(\mathrm{OM}<0.67$, having sandy loam, loam, or loamy sand texture). Values of $K_{O M}$ reported by Vagi et al (2010) predicted that dimethoate was mobile in some Greek soils. Many other researchers have also predicted the mobility of organophosphorus pesticides in the soil on the basis of the $K_{O M}$ value (Islam et al., 2010; Rotich et al., 2004; Vagi et al., 2010). The experimental results showed that the adsorption capacity of dimethoate increased with an increase in organic matter of the soil. In general, the values of $K_{O M}$ of the present study are almost the same as those reported in literature. The $\log K_{O M}$ values of the present study varying from 2.38 to 2.74 are in agreement with those reported in literature (Vagi et al., 2010).

The $K_{O M}$ and $\Delta G_{O M}^{\circ}$ can be related by Eq. (12):

$$
\Delta G_{O M}^{\circ}=-R T \ln K_{O M},
$$

where: $\Delta G_{O M}^{\circ}$ is the organic matter normalized free energy change in adsorption $\left(\mathrm{kJ} \mathrm{mol}^{-1}\right)$.

The $\Delta G_{O M}^{\circ}$ values obtained in the present study are also listed in Table 4. All the values were negative indicating that the process was spontaneous and thermodynamically

T a b l e 4. Values of $K_{O M}, \log \left(K_{O M}\right)$, and $\Delta G^{\circ}$ OM for adsorption of dimethoate on various Indian soils at different temperatures

\begin{tabular}{cccccccccc}
\hline Soil No. & $\begin{array}{c}K_{O M} \\
\left(\mathrm{~kg} \mathrm{l}^{-1}\right)\end{array}$ & $\log \left(K_{O M}\right)$ & $\begin{array}{c}\Delta G_{\text {OM }}^{\circ} \\
\left(\mathrm{kJ} \mathrm{mol}^{-1}\right)\end{array}$ & $\begin{array}{c}K_{O M} \\
\left(\mathrm{~kg} \mathrm{l}^{-1}\right)\end{array}$ & $\log \left(K_{O M}\right)$ & $\begin{array}{c}\Delta \mathrm{G}_{\text {OM }}^{\circ} \\
\left(\mathrm{kJ} \mathrm{mol}^{-1}\right)\end{array}$ & $\begin{array}{c}K_{O M} \\
\left(\mathrm{~kg} \mathrm{l}^{-1}\right)\end{array}$ & $\log \left(K_{O M}\right)$ & $\begin{array}{c}\Delta \mathrm{G}_{\mathrm{OM}}^{\circ} \\
\left(\mathrm{kJ} \mathrm{mol}^{-1}\right)\end{array}$ \\
\hline A & $20^{\circ} \mathrm{C}$ & & & $30^{\circ} \mathrm{C}$ & & & $40^{\circ} \mathrm{C}$ & \\
B & 511.93 & 2.71 & -15.20 & 405.79 & 2.61 & -15.13 & 278.25 & 2.44 & -14.65 \\
C & 489.25 & 2.69 & -15.09 & 375.82 & 2.57 & -14.94 & 241.34 & 2.38 & -14.28 \\
\hline
\end{tabular}


favourable. The values changed from -15.20 to -14.65 , -15.09 to -14.28 , and -15.37 to $-14.67 \mathrm{~kJ} \mathrm{~mol}^{-1}$ as the temperature changed from 20 to $40^{\circ} \mathrm{C}$ for loamy (A), loamy sand (B), and sandy loam (C) soils, respectively. Therefore, an increase in temperature can result in a decrease in adsorption. Furthermore, the negative $\Delta G_{O M}^{\circ}$ values indicated that physical adsorption was carried out by involving weak forces of attraction between pesticide molecules and soil surface.

Thermodynamic considerations of the adsorption process are necessary to conclude whether the process is spontaneous or not. The thermodynamic parameters such as $\Delta G^{\circ}$, $\Delta H^{\circ}$, and $\Delta S^{\circ}$ provide additional information regarding energetic changes involved during the temperature-dependent sorption (Broznic and Milin, 2012). The Gibbs free energy change $\Delta G^{\circ}$ was calculated as:

$$
\Delta G^{\circ}=-R T \ln K_{d} .
$$

The partitioning coefficient $K_{d}$ of the pesticide toward a soil is an important parameter for examining the contaminant migration through the soil to the groundwater. If the $K_{d}$ value is low, the soil has little or no ability to slow the contaminant movement. For a $K_{d}$ value of zero, it will travel at the rate of infiltration of water. High $K_{d}$ values signify that the substrate does not leach and site remediation may be possible.

As suggested by Roth et al. (2012), $K_{d}\left(1 \mathrm{~mol}^{-1}\right)$ in batch experiments is calculated as:

$$
K_{d}=\frac{M Q_{e}}{C_{e}},
$$

where: $M$ is the molecular weight of the pesticide (229.63).

Defining the $K_{d}$ as above implies that the adsorption of the pesticide is a linear isotherm model. However, this is an approximation at a low initial pesticide concentration and adsorption on soil often deviates from linearity.

As $K_{d}$ is concentration dependent (the adsorption process is not linear), thermodynamic calculations are obtained by plotting $\ln K_{d}$ versus $C_{e}$ and extrapolating to zero.

The other thermodynamic parameters can be calculated by Eq. (15):

$$
\Delta G^{\circ}=\Delta H^{\circ}-T \Delta S^{\circ},
$$

where: $\Delta H^{\circ}$ and $\Delta S^{\circ}$ are the changes in enthalpy and entropy of adsorption.

The $\Delta G^{o}$ value is an indication of spontaneity of a chemical reaction and therefore is an important criterion for spontaneity. Reactions occur spontaneously at a given temperature if $\Delta G^{o}$ is a negative quantity. The values of three different thermodynamic parameters $\Delta G^{\circ}, \Delta H^{\circ}$, and $\Delta S^{\circ}$ for dimethoate are presented in Table 5. The $\Delta G^{\circ}$ values ranged from -15.34 to $-16.60 \mathrm{~kJ} \mathrm{~mol}^{-1}$ for all the studied soils. The absolute values decreased with an increase in temperature of adsorption indicating that the adsorption decreased with the rise in temperature. The change in the $\Delta G^{\circ}$ value may be due to the increase in the degree of freedom, which might have enhanced desorption rather than adsorption at higher temperatures.

The $\Delta H^{\circ}$ value in the range of 4 to $8 \mathrm{~kJ} \mathrm{~mol}^{-1}$ indicates the existence of van der Waals interactions, whereas H-bonds are main interactions in the range of 8 to $40 \mathrm{~kJ} \mathrm{~mol}^{-1}$ (Broznic and Milin, 2012). The $\Delta H^{\circ}$ values associated with chemical sorption are usually higher than $40 \mathrm{~kJ} \mathrm{~mol}^{-1}$. In the present study, the $\Delta H^{\circ}$ values were negative and varied from -23.39 to $-32.95 \mathrm{~kJ} \mathrm{~mol}^{-1}$. This shows that the adsorption process was exothermic in nature and occurred through a bonding mechanism indicating the participation of amino and carbonyl groups in dimethoate with other O- and Natoms present in soil colloids. The results of the study also indicated that the interactions between dimethoate and soils were stronger at lower temperatures. The small negative values of $\Delta S^{\circ}$ (from -25.7 to $-55.9 \mathrm{~J} \mathrm{~mol}^{-1} \mathrm{~K}^{-1}$ ) suggested decreased randomness on the solid/solute interface during the adsorption of dimethoate on the studied soils.

Leaching is a downward movement of a substance with water through the soil. The main factors that influence the leaching of a pesticide in the soil are adsorption of the pesticide on soil surface, water solubility of the pesticide, the volume of water flow, and soil texture (Crisanto et al., 2000). The desorption data was also fitted to the Freundlich isotherm model using Eq. (16):

$$
Q_{e}^{\text {des }}=K_{f}^{\text {des }}\left(C_{e}^{\text {des }}\right)^{1 / n},
$$

where: $K_{f}^{\text {des }}$ and $n$ are Freundlich desorption isotherm con-

\begin{tabular}{|c|c|c|c|c|}
\hline \multirow{2}{*}{ Soil No. } & \multirow{2}{*}{$\begin{array}{c}\text { Temperature } \\
\left({ }^{\circ} \mathrm{C}\right)\end{array}$} & $\Delta G^{\circ}$ & $\Delta H^{\circ}$ & $\Delta S^{\circ}$ \\
\hline & & \multicolumn{3}{|c|}{$\left(\mathrm{kJ} \mathrm{mol}^{-1}\right)$} \\
\hline \multirow{3}{*}{ A } & 20 & -16.60 & \multirow{3}{*}{-32.95} & \multirow{3}{*}{-55.9} \\
\hline & 30 & -15.93 & & \\
\hline & 40 & -15.48 & & \\
\hline \multirow{3}{*}{ B } & 20 & -16.27 & \multirow{3}{*}{-27.73} & \multirow{3}{*}{-38.70} \\
\hline & 30 & -16.19 & & \\
\hline & 40 & -15.50 & & \\
\hline \multirow{3}{*}{$\mathrm{C}$} & 20 & -15.85 & \multirow{3}{*}{-23.39} & \multirow{3}{*}{-25.70} \\
\hline & 30 & -15.59 & & \\
\hline & 40 & -15.34 & & \\
\hline
\end{tabular}
stants. The extent of hysteresis can be obtained for every

T a b l e 5. Values of thermodynamic parameters obtained for dimethoate adsorption on studied soils at different temperatures 
set of adsorption and desorption isotherms using the hysteresis coefficient $H$ (Cox et al., 1997). The $H$ value was calculated as:

$$
H=\frac{1 / n_{\text {des }}}{1 / n_{\text {ads }}},
$$

Desorption isotherms of dimethoate on the studied soils at different temperatures are shown in Fig. 3. The related Freundlich coefficients and $\mathrm{R}^{2}$ values along with the hysteresis coefficients are given in Table 6. Desorption isotherms looked similar to those of adsorption isotherms although the values of Freundlich coefficients differed significantly. As compared to the adsorption isotherm coefficients, the $K_{f}$ values increased and the $1 / n$ values decreased in desorption isotherms. The Freundlich isotherm $m$ was fitted better to the desorption process than to the adsorption process as indicated by the $\mathrm{R}^{2}$ value (Tables 3 and 6 ). As shown in Table 6 , the $K_{f}$ values decreased as the temperature increased from 20 to $40^{\circ} \mathrm{C}$ in all the soils indicating that temperature strongly affected the desorption process. The $1 / n$ value ranged between 0.702 and 0.825 in the studied range of temperatures. This value indicated that 17.5 to $30 \%$ deviation from linear function took place in the fitted isotherms. In order to find out differences in adsorption and desorption isotherms, the hysteresis coefficient $H$ was calculated. The hysteresis phenomenon is characterized by differences in the slopes of adsorption and desorption isotherms. A lower $H$ value indicates that the adsorptiondesorption phenomenon is more pronounced with high nonlinearity and therefore the desorption rate is slower in relation to the adsorption rate (Broznic and Milin, 2012). In the present study, as evident from Table 6, the hysteresis existed and the $H$ value ranged between 0.712 and 0.828 . In general, this phenomenon was less pronounced at $40^{\circ} \mathrm{C}$ as compared to 20 and $30^{\circ} \mathrm{C}$.

Mass balances for dimethoate were made by using the data collected from adsorption and desorption studies and the results are presented in Table 7. The percent mass balance indicated that during the adsorption process, nearly $60 \%$ of the initial pesticide amount remained free in all the studied soils even at $20^{\circ} \mathrm{C}$ and this amount increased further as the temperature increased. This indicates the chances of surface water contamination through run off and groundwater contamination in all the studied soils. The percent dimethoate desorbing with water increased with the increasing initial concentration level as well as with temperature in all the soils although the extent of the release of the pesticide varied. Therefore, irrespective of the soil, temperature affected the desorption process significantly. The higher
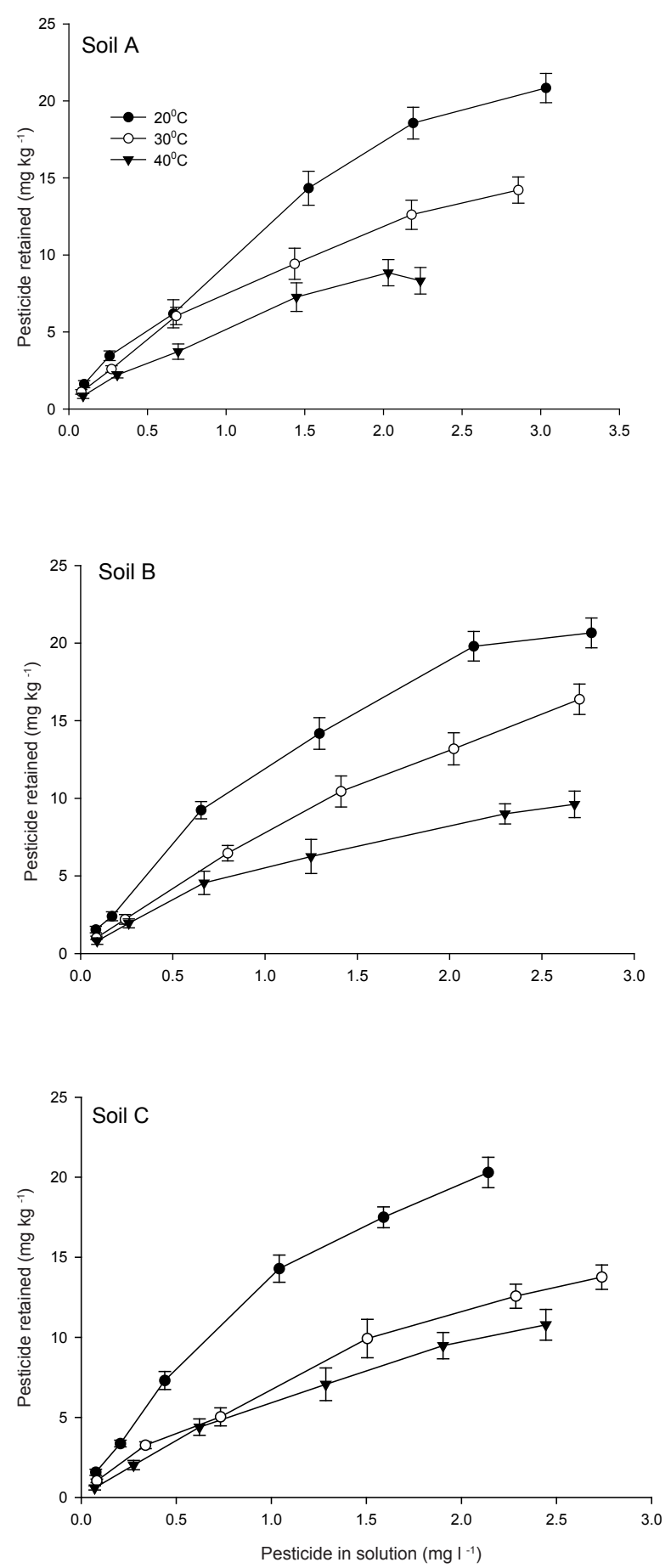

Fig. 3. Desorption isotherm plots of dimethoate on various soils at different temperatures. Error bars show standard deviation.

temperature can cause more surface water contamination partly by free pesticide remaining in water during adsorption and partly by higher release of the adsorbed pesticide during desorption. 
T a b I e 6. Freundlich desorption coefficients along with coefficients of determination $\left(\mathrm{R}^{2}\right)$ and hysteresis index $(H)$ for dimethoate desorption at different temperatures

\begin{tabular}{|c|c|c|c|c|c|c|c|c|c|c|c|c|}
\hline \multirow{3}{*}{$\begin{array}{l}\text { Soil } \\
\text { No. }\end{array}$} & $K_{f}$ & $1 / n$ & $\mathrm{R}^{2}$ & $H$ & $K_{f}$ & $1 / n$ & $\mathrm{R}^{2}$ & $\mathrm{H}$ & $K_{f}$ & $1 / n$ & $\mathrm{R}^{2}$ & $H$ \\
\hline & \multicolumn{12}{|c|}{ Temperature $\left({ }^{\circ} \mathrm{C}\right)$} \\
\hline & \multicolumn{4}{|c|}{20} & \multicolumn{4}{|c|}{30} & \multicolumn{4}{|c|}{40} \\
\hline A & 9.528 & 0.766 & 0.994 & 0.747 & 7.106 & 0.728 & 0.995 & 0.728 & 5.067 & 0.739 & 0.994 & 0.740 \\
\hline B & 10.800 & 0.782 & 0.988 & 0.784 & 7.493 & 0.822 & 0.998 & 0.828 & 5.124 & 0.731 & 0.989 & 0.712 \\
\hline $\mathrm{C}$ & 12.410 & 0.789 & 0.991 & 0.825 & 6.810 & 0.741 & 0.825 & 0.702 & 5.661 & 0.825 & 0.994 & 0.766 \\
\hline
\end{tabular}

T a b l e 7. Mass percent balances for adsorbed, free or non-adsorbed and desorbed with water dimethoate in soils under study at different temperatures

\begin{tabular}{|c|c|c|c|c|c|c|c|c|c|c|}
\hline \multirow{3}{*}{$\begin{array}{l}\text { Soil } \\
\text { No. }\end{array}$} & \multirow{3}{*}{$\begin{array}{c}\text { Initial } \\
\text { concentration } \\
\text { level } \\
\left(\mathrm{mg} \mathrm{l}^{-1}\right)\end{array}$} & $\begin{array}{l}\text { Adsorbed } \\
\text { amount } \\
\left(\mathrm{mg} \mathrm{kg}^{-1}\right)\end{array}$ & $\begin{array}{c}\text { Free } \\
\text { or not } \\
\text { adsorbed } \\
(\%)\end{array}$ & $\begin{array}{c}\text { Desorbed } \\
\text { with } \\
\text { water } \\
(\%)\end{array}$ & $\begin{array}{l}\text { Adsorbed } \\
\text { amount } \\
\left(\mathrm{mg} \mathrm{kg}^{-1}\right)\end{array}$ & $\begin{array}{c}\text { Free } \\
\text { or not } \\
\text { adsorbed } \\
(\%)\end{array}$ & $\begin{array}{c}\text { Desorbed } \\
\text { with } \\
\text { water } \\
(\%)\end{array}$ & $\begin{array}{l}\text { Adsorbed } \\
\text { amount } \\
\left(\mathrm{mg} \mathrm{kg}^{-1}\right)\end{array}$ & $\begin{array}{c}\text { Free } \\
\text { or not } \\
\text { adsorbed } \\
(\%)\end{array}$ & $\begin{array}{c}\text { Desorbed } \\
\text { with } \\
\text { water } \\
(\%)\end{array}$ \\
\hline & & \multicolumn{9}{|c|}{ Temperature $\left({ }^{\circ} \mathrm{C}\right)$} \\
\hline & & \multicolumn{3}{|c|}{20} & \multicolumn{3}{|c|}{30} & \multicolumn{3}{|c|}{40} \\
\hline \multirow{6}{*}{ A } & 1 & 2.10 & 58.00 & 23.11 & 1.50 & 70.00 & 26.31 & 1.30 & 74.00 & 35.17 \\
\hline & 2 & 4.75 & 52.50 & 27.22 & 3.95 & 60.50 & 34.32 & 3.75 & 62.50 & 41.04 \\
\hline & 5 & 9.50 & 62.00 & 34.96 & 9.45 & 62.20 & 36.12 & 7.20 & 71.20 & 48.26 \\
\hline & 10 & 21.95 & 56.10 & 34.71 & 16.60 & 66.80 & 43.23 & 14.50 & 71.00 & 49.91 \\
\hline & 15 & 29.50 & 60.67 & 37.09 & 23.50 & 68.67 & 46.34 & 19.00 & 74.67 & 53.44 \\
\hline & 20 & 36.00 & 64.00 & 42.12 & 28.50 & 71.50 & 50.13 & 19.50 & 80.50 & 57.31 \\
\hline \multirow{6}{*}{ B } & 1 & 1.95 & 61.00 & 21.15 & 1.44 & 71.18 & 29.82 & 1.25 & 75.00 & 35.76 \\
\hline & 2 & 3.25 & 67.50 & 26.15 & 3.40 & 66.00 & 35.33 & 3.25 & 67.50 & 40.23 \\
\hline & 5 & 12.50 & 50.00 & 26.12 & 10.45 & 58.20 & 38.14 & 7.90 & 68.40 & 42.35 \\
\hline & 10 & 20.65 & 58.70 & 31.34 & 17.50 & 65.00 & 40.32 & 12.50 & 75.00 & 49.97 \\
\hline & 15 & 30.45 & 59.40 & 34.98 & 23.30 & 68.93 & 43.40 & 20.50 & 72.67 & 56.10 \\
\hline & 20 & 34.50 & 65.50 & 40.12 & 29.90 & 70.10 & 45.21 & 23.00 & 77.00 & 58.21 \\
\hline \multirow{6}{*}{$\mathrm{C}$} & 1 & 1.95 & 61.00 & 19.52 & 1.45 & 71.00 & 28.32 & 0.95 & 81.00 & 37.54 \\
\hline & 2 & 4.40 & 56.00 & 23.45 & 4.95 & 50.50 & 34.14 & 3.40 & 66.00 & 40.61 \\
\hline & 5 & 9.50 & 62.00 & 23.12 & 8.70 & 65.20 & 42.12 & 7.50 & 70.00 & 41.43 \\
\hline & 10 & 19.50 & 61.00 & 26.70 & 17.45 & 65.10 & 43.12 & 13.50 & 73.00 & 47.65 \\
\hline & 15 & 25.45 & 66.07 & 31.24 & 24.00 & 68.00 & 47.62 & 19.00 & 74.67 & 50.10 \\
\hline & 20 & 31.00 & 69.00 & 34.53 & 27.45 & 72.55 & 49.87 & 23.00 & 77.00 & 53.13 \\
\hline
\end{tabular}




\section{CONCLUSIONS}

1. Sorption behaviour of dimethoate pesticide in various Indian soils show that the experimental kinetic data revealed that equilibrium was reached within $15 \mathrm{~h}$ in all the soils under study and the adsorption process could be described by the pseudo second order kinetic model.

2. The equilibrium adsorption isotherms belonged to the Freundlich model and were S-shaped, describing the reversible, non-uniform, and multilayer adsorption over the heterogeneous surface. The desorption process could also be explained by the Freundlich isotherm model and was strongly affected by temperature and pesticide concentration levels.

3. The decrease in the Freundlich coefficient $K_{f}$ with the increase in temperature indicated that the adsorption process was strongly affected by temperature. The $K_{f}$ was positively correlated with organic matter content and electrical conductivity of soil.

4. Thermodynamic analysis showed that the adsorption process was spontaneous and exothermic in nature. Relatively weak $\mathrm{H}$-bond forces were the main driving forces in the adsorption process.

5. The surface as well as groundwater resources are vulnerable to dimethoate contamination partly due to low adsorption by soil and partly due to higher release of adsorbed pesticide especially at higher temperature.

6 . The information obtained can be useful in development of models for predicting the dimethoate behaviour in soil and aqueous media as well as controlled application thereof in order to minimize environmental contamination.

\section{REFERENCES}

Ahmad R. and Kumar R., 2011. Adsorption of amaranth dye onto alumina reinforced polystyrene. Clean-Soil Air Water, 39(1), 74-82.

Anderson P.N., Eaton D.L., and Murphy S.D., 1992. Comparative metabolism of methyl parathion in intact and subcellular fractions of isolated rat hepatocytes. Fundam. Appl. Toxicol., 18(2), 221-226.

Bajeer M.A., Nizamani S.M., Sherazi S.T.H., and Bhanger M.I., 2012. Adsorption and Leaching Potential of Imidacloprid Pesticide through Alluvial Soil. Am. J. Anal. Chem., 3(8), 604-611.

Batista S., Silva E., Galhardo S., Viana P., and Cerejeira M.J., 2002. Evaluation of Pesticide Contamination of Ground Water in Two Agricultural Areas of Portugal. Int. J. Environ. Anal. Chem., 82(8-9), 601-609.

Bouyoucos G.J., 1962. Hydrometer method improved for making particle size analysis of soils. Agron. J., 54(5), 464-465.

Broznic D. and Milin C., 2012. Effect of temperature on sorptiondesorption processes of imidacloprid in soils of Croatian coastal regions. J. Environ. Sci. Health., 47(8), 779-794.

Calvet R., 1989. Adsorption of organic chemicals in soils. Environ. Health Perspect., 83(3-4), 145-177.
Carter M.R., 1993. Soil Sampling and Methods of Analysis. Canadian Society of Soil Science Publications, Ottawa, Ontario, Canada.

Cox L., Koskinen W.C., and Yen P.Y., 1997. Sorption-desorption of imidacloprid and its metabolites in soils. J. Agri. Fd. Chem., 45(4), 1468-1472.

Crisanto T., Sanchez-Martin M.J., and Sanchez-Camazano M., 2000. Mobility of pesticides in soils. Influence of soil properties and pesticide structure. Toxicological. Environ. Chemistry, 47, 97-104.

EIShafei G.S., Nasr I.N., Hassan A.S.M., and Mohammad S.G.M., 2009. Kinetics and thermodynamics of adsorption of cadusafos on soils. J. Hazard. Mater., 172(2-3), 1608-1616.

Gao J.P., Maguhn J., Spitzauer P., and Kettrup A., 1998. Sorption of Pesticides in the Sediment of the Teufelesweiher Pond (Southern Germany). I: Equilibrium Assessments, Effect of Organic Carbon Content and $\mathrm{pH}$. Water Res., 32(5), 1662-1672.

Garg U., Kaur M.P., Jawa G.K., Sud D., and Garg V.K., 2008. Removal of cadmium (II) from aqueous solutions by adsorption on agricultural waste biomass. J. Hazard. Mater., 154(1-3), 1149-1157.

Giles C.H., McEvan T.H., Nakhwa S.N., and Smith D., 1960. Studies in adsorption. Part XI, A System of classification on solution adsorption isotherms, and its use in diagnosis of adsorption mechanism and in measurement of specific surface areas of solids. J. Chem. Soc., 1, 3973-3993.

Hance R.J., 1977. The adsorption of atraton and momuron by soils at different water contents. Weed Res., 17, 137-201.

Islam M.A., Sakkas V., and Albanis T., 2010. Adsorptiondesorption study of bromophos methyl and quinalphos in Greek soils. Int. J. Environ. Anal. Chem., 90(3-6), 357-368.

Ismail B.S., Enoma A.O.S., Cheah U.B., Lum K.Y., and Malik Z., 2002. Adsorption, desorption, and mobility of two insecticides in Malaysian agricultural soil. J. Environ. Sci. Health., 37(4), 355-364.

Kaur P. and Sud D., 2010. Adsorption kinetics, isotherms, and desorption of monocrotophos and dichlorvos on various Indian soils. Clean - Soil Air Water, 39(12), 1060-1067.

Krishna K.R. and Philip L., 2008. Adsorption and desorption characteristics of lindane, carbofuran and methyl parathion on various Indian soils. J. Hazard. Mater., 160(2-3), 559-567.

Kuisi M.A., 2002. Adsorption of dimethoate and 2,4-D on Jordan valley soils and their environmental impact. Environ. Geology, 42(6), 666-667.

Lalah J.O., Njogu S.N., and Wandiga S.O., 2009. The effect of $\mathrm{Mn}^{2+}, \mathrm{Ni}^{2+}, \mathrm{Cu}^{2+}, \mathrm{Co}^{2+}$ and $\mathrm{Zn}^{2+}$ ions on pesticide adsorption and mobility in a tropical soil. Bull. Environ. Contam. Toxicol., 83, 352-358.

Liu L.C., Cibes-Viade H., and Koo F.K.S., 1970. Adsorption of ametryne and diuron by soils. Weed Sci., 18(4), 470-474.

OECD (Organization for Economic Co-operation and Development), 2000. In OECD Guidelines for Testing of Chemicals - Test Guideline 106: Adsorption-desorption using batch equilibrium method in Soils, Environ. Health and Safety Division, OECD Environ. Directorate, Paris, France. 
Oladoja N.A., Aboluwoye C.O., and Oladimeji Y.B., 2008. Kinetics and isotherm studies on methylene blue adsorption onto ground palm kernel coat. Turk. J. Eng. Environ. Sci., 32(5), 303-312.

Parr T.F. and Smith S., 1974. Degradation of DDT in an evergardes muck as affected by lime, ferrous ion and aerobiosis. Soil Sci., 118, 45-51.

Patakioutas G. and Albanis T.A., 2002. Adsorption-desorption studies of alachlor, metolachlor, EPTC, chlorothalonil and pirimiphos-methyl in contrasting soils. Pest Manag. Sci., 58(4), 352-362.

Peng F., He P.W., Luo Y., Lu X., Liang Y., and Fu J., 2012. Adsorption of Phosphate by Biomass Char Deriving from Fast Pyrolysis of Biomass Waste. Clean - Soil Air Water, 40(5), 493-498.

Roth E., Mancier V., and Fabre B. 2012. Adsorption of cadmium on different granulometric soil fractions: Influence of organic matter and temperature. Geoderma, 189-190, 133-143.

Rotich H.K., Zhang Z., Zhao Y., and Li J., 2004. The adsorption behaviour of three organophosphorus pesticides in peat and soil samples and their degradation in aqueous solutions at different temperatures and $\mathrm{pH}$ values. Int. J. Environ. Anal. Chem., 84(4), 289-301.

Ryan D.K., Thompson C.R., and Weber J.H., 1983. Comparison of $\mathrm{Mn}^{2+}, \mathrm{Co}^{2+}$ and $\mathrm{Cu}^{2+}$ binding to fulvic acids as measured by fluorescence quenching, Can. J. Chem., 61, 1505-1509.
Swann R.L., Laskowski D.A., McCall P.J., Kuy K.V., and Dishburger H.J., 1983. A rapid method for the estimation of the environmental parameters octanol/water partition coefficient, soil sorption constant, water to air ratio, and water solubility. Residue Rev., 85, 17-28.

Vagi M.C., Petsas A.S., Kostopoulou M.N., and Lekkas T.D., 2010. Adsorption and desorption processes of the organophosphorus pesticides, dimethoate and fenthion, onto three Greek agricultural soils. Int. J. Environ. Anal. Chem., 90(36), 369-389.

Vig K., Singh D.K., Agarwal H.C., Dhawan A.K., and Dureja P., 2001. Insecticide residues in cotton crop soil. J. Environ. Sci. Health., 36(4), 421-434.

Von O.B., Kordel W., and Klein W., 1991. Sorption of nonpolar and polar compounds to soils: Processes, measurement and experience with the applicability of the modified OECDguidelines. Chemosphere, 22(3-4), 285-304.

Weber J.R. and Morris J.C., 1963. Kinetics of adsorption on carbon from solutions. J. Sanit. Eng. Div. Am. Soc. Civ. Eng., 89, 31-59.

Weber W.J.J., McGinley P.M., and Katz L.E., 1991. Sorption phenomena in subsurface systems: Concepts, models and effects on contaminant fate and transport. Water Res., 25(5), 499-528.

Yaron B. and Saltzman S., 1972. Influence of water and temperature on adsorption of parathion by soil. Soil Sci. Soc. Am. J., 36(3), 536-538. 